\title{
Burden of respiratory tract infections at post mortem in Zambian children
}

\author{
Matthew Bates ${ }^{1,2,10^{*}}$, Aaron Shibemba ${ }^{3}$, Victor Mudenda ${ }^{3}$, Charles Chimoga ${ }^{1,2}$, John Tembo ${ }^{1,2,4}$, Mwila Kabwe ${ }^{1,2}$, \\ Moses Chilufya ${ }^{1,2}$, Michael Hoelscher ${ }^{5}$, Markus Maeurer ${ }^{6}$, Sylvester Sinyangwe', Peter Mwaba ${ }^{2,8}$, \\ Nathan Kapata ${ }^{2,9}$ and Alimuddin Zumla 2,10
}

\begin{abstract}
Background: Autopsy studies are the gold standard for determining cause-of-death and can inform on improved diagnostic strategies and algorithms to improve patient care. We conducted a cross-sectional observational autopsy study to describe the burden of respiratory tract infections in inpatient children who died at the University Teaching Hospital in Lusaka, Zambia.

Methods: Gross pathology was recorded and lung tissue was analysed by histopathology and molecular diagnostics. Recruitment bias was estimated by comparing recruited and non-recruited cases.

Results: Of 121 children autopsied, $64 \%$ were male, median age was 19 months (IQR, 12-45 months). HIV status was available for 97 children, of whom $34 \%$ were HIV infected. Lung pathology was observed in $92 \%$ of cases. Bacterial bronchopneumonia was the most common pathology (50\%) undiagnosed ante-mortem in $69 \%$ of cases. Other pathologies included interstitial pneumonitis (17\%), tuberculosis (TB; $8 \%)$, cytomegalovirus pneumonia (7 \%) and pneumocystis Jirovecii pneumonia (5\%). Comorbidity between lung pathology and other communicable and non-communicable diseases was observed in $80 \%$ of cases. Lung tissue from $70 \%$ of TB cases was positive for Mycobacterium tuberculosis by molecular diagnostic tests. A total of $80 \%$ of TB cases were comorbid with malnutrition and only $10 \%$ of TB cases were on anti-TB therapy when they died.
\end{abstract}

Conclusions: More proactive testing for bacterial pneumonia and TB in paediatric inpatient settings is needed.

Keywords: Autopsy, Post mortem, Children, Zambia, Africa, Tuberculosis, Pneumonia, Cytomegalovirus, Pneumocystis Jirovecii pneumonia

\section{Background}

Global Burden of Disease study estimates suggest that, for children, bacterial pneumonia is the leading single cause of death, responsible for $23 \%$ of deaths in children aged between 27 days and 5 years of age [1]. Respiratory pathology may also play a role in additional deaths, as bacterial, fungal or viral lung infections may underlie other major causes of death, including infections such as malaria or diarrhoeal disease, as well as non-communicable diseases such as malnutrition [2-4]. Determining the aetiology of childhood respiratory deaths in the African

\footnotetext{
* Correspondence: matthew.bates@ucl.ac.uk

${ }^{1}$ HerpeZ, University Teaching Hospital, Lusaka, Zambia

${ }^{2}$ University of Zambia and University College London Medical School (UNZA-UCLMS) Research and Training Programme, University Teaching Hospital, Lusaka, Zambia

Full list of author information is available at the end of the article
}

context is particularly challenging - symptoms are nonspecific, obtaining specimens for microbiological analysis from infants and young children ante mortem is difficult, and in the low-resource settings laboratory services cannot provide a thorough microbiological work-up combining culture with the latest multiplex molecular diagnostics $[4,5]$. It is hence extremely difficult for the attending physician to differentiate between bacterial, mycobacterial, fungal or viral aetiologies [6,7]. The non-specific symptoms of respiratory infections also contribute to the inaccuracy of verbal autopsy studies, which rely on interviewing relatives or the attending physician [8].

The gold-standard for determining cause-of-death is anatomical post mortem followed by histopathological examination of selected tissues [9]. Post mortem studies have been rarely undertaken in the African context 
because they are expensive and difficult to implement, requiring highly skilled personnel and sophisticated infrastructure, and because they are culturally unpalatable, particularly with respect to children $[4,10,11]$. Furthermore, the results of autopsy studies are often overlooked by epidemiologists due to the relatively small sample sizes compared to larger and easier to implement surveys of clinical records and verbal autopsy studies. However, when autopsy studies have been undertaken, they often yield surprising results. In 2002, we conducted a landmark autopsy study of 264 Zambian paediatric deaths [12], which influenced World Health Organization policy with respect to the burden of paediatric tuberculosis (TB), and led to studies to treat Pneumocystis Jirovecii pneumonia (PCP) in HIV-infected children [13].

The decade that followed has seen the roll out of antiretroviral therapy (ART) and prevention of mother-to-child transmission programmes. We conducted a prospective autopsy study to describe the histopathological and microbiological findings derived from the examination of lungs at post mortem among inpatient children who died at the University Teaching Hospital (UTH), Lusaka, Zambia.

\section{Methods}

\section{Study design}

We undertook a cross-sectional autopsy study of inpatient paediatric deaths at UTH, Zambia's national referral centre, to determine the burden of respiratory pathology among children dying at the hospital. All children $<15$ years of age who died in the inpatient wards at UTH were eligible for inclusion in the study. Necropsy restricted to the chest cavity was performed. Autopsy findings and outcome data on respiratory causes-ofdeath were compared with the cause-of-death given by the attending physician. Baseline age and sex of all inpatient paediatric deaths during the recruitment period was extracted from hospital mortality records to allow a rough estimate of how the study group might be representative of all paediatric mortalities within the hospital.

\section{Recruitment and consent}

The recruitment process takes several hours and involves counselling the relatives and talking about the child who has died, before then introducing the idea of the autopsy investigation and explaining the purpose and rationale of the study. Due to time constraints, it was not possible to approach the relatives of all children who died during the study period. The recruiting clinical officer (CC) worked Monday to Friday and so the relatives of children who died between Friday afternoon and Sunday morning were unlikely to be approached to take part in the study. In Zambia, there is a cultural requirement that there be minimal delay in burying children. After being alerted to deaths by the attending physician, our multi-lingual clinical officer would approach the relatives to offer counselling, introducing them to the study in their native language and providing them with written information sheets (available in English, Chi-Nyanja and Chi-Bemba) explaining the purpose of the study. The attending relatives were given the opportunity to consult with family elders and to ask any questions they might have, and reasons for refusing consent were recorded. Consenting families were given a payment of $\$ 10$ to compensate for the delayed release of the deceased for burial. The HIV status of the children in this study is taken from either neonatal PCR testing (in children under 18 months of age) and/or standard serology testing in accordance with Zambian national guidelines in children aged 18 months and older. Ethical approval for the study was granted by the University of Zambia Biomedical Research Ethics Committee.

\section{Autopsy examination and sampling}

One of two consultant pathologists (VM and AS) undertook a limited necropsy examination within 18 hours after death, examining the lungs, intrathoracic lymph nodes, heart, kidneys, pancreas, spleen and liver. Gross pathology was recorded and photographed, organs weighed and dissected, with lung samples taken for histopathology and aseptically for cryopreservation (stored at $-80{ }^{\circ} \mathrm{C}$ ), employing strict safety procedures as previously described [14]. Samples were obtained from all five lobes guided by gross pathology. In the absence of gross pathology a representative specimen was sampled.

\section{Histopathology}

Histopathologists, blinded to clinical data, performed haematoxylin and eosin, silver methenamine, periodic acidSchiff and Zeihl-Neelsen stains as previously described [14]. Pathological findings were defined as described $[14,15]$. Post mortem diagnoses were based on a composite of gross pathology and histopathology. Cultures were not undertaken as the UTH TB lab had insufficient capacity to culture TB from tissue specimens within the timeframe of study commencement, and also because a negative culture does not exclude TB disease at autopsy. Zeihl-Neelsen stains were undertaken on all suspected TB cases.

\section{Molecular analysis}

Cryopreserved lung tissue was analysed with the Xpert MTB/RIF assay as previously described [14]. This cartridge based molecular diagnostic test detects Mycobacterium tuberculosis (M.tb) complex DNA and rifampicin resistance, a reasonable proxy marker of multi-drug resistant-TB [16, 17]. For non-TB mycobacteria (NTM) analysis, DNA was extracted from cryopreserved lung tissue using the 'E0101 DNA extraction kit', and screened 
with the 'PowerChek ${ }^{\text {Tw }}$ MTB/NTM Real-time PCR Kit' (both supplied by Kogene, South Korea), in accordance with manufacturer's instructions. This internally controlled Real-Time PCR assay uses a generic pan-mycobacteria probe (target 16S-23S rRNA internal transcribed spacer (ITS) region) and an M.tb specific probe(target IS6110) to differentiate $M . t b$ from NTM.

\section{Data management and statistical analysis}

We undertook double-data entry using Epidata and exported cleaned datasets for analysis in SPSS version 21. Point prevalences were weighted based on the age distribution and sex of the population of deaths at the hospital as previously described [14].

\section{Results}

\section{Case recruitment and descriptives}

During the study period (August 2011 to June 2014) there were a total of 3725 deaths among paediatric admissions under 15 years of age. The recruiting clinical officer approached 1471 families and obtained consent for participation in the study from 121 families (Fig. 1). The main reasons for refusing consent were time constraints on taking the child for burial and loss to followup after agreeing to consult with family (Fig. 1). Of 121 children autopsied, $60 \%(73 / 121)$ of cases were male, median age was 19 months (IQR, 12-45 months), and $35 \%(34 / 96)$ of children were HIV infected (Table 1). ART status was determined for 24 cases, of which $63 \%$ (15) were on ART when they died. Overall, $12 \%(15 / 121)$ of children were receiving anti-TB therapy. Comparing age and sex between study and non-study mortalities, we found that the age distribution of participants in our study was significantly older and that the percentage of male children was higher $(60 \%, 73 / 121)$ than among non-study deaths (50\%, 1810/3604; $P=0.029$; Table 1$)$. The median duration of stay in hospital was 2 days (IQR, 1-6 days).

\section{Lung pathologies and stratification by HIV status}

Lung pathology was observed in $92 \%(111 / 121)$ of cases (Table 2). Bronchopneumonia was the most common finding, diagnosed in $50 \%(60 / 121)$ of cases, followed by interstitial pneumonitis in $17 \%(20 / 121)$. TB was detected in $8 \%(10 / 121)$ of all deaths (9 pulmonary and 1 extrapulmonary), and was two-fold more prevalent in HIV-infected children, although within the limits of the sample this was not significant $(P=0.15)$. Furthermore, infections that are commonly associated with HIV, such as cytomegalovirus pneumonia, pneumocystis Jirovecii pneumonia and candidiasis, were not more prevalent among HIV-infected children, within the limits of the available sample (Table 2). Adjusting for recruitment bias did not significantly affect the distribution of lung pathologies (Table 2).

\section{Comparison between lung pathology and diagnosis given by the attending physician}

We identified comorbidity between two or more communicable and non-communicable diseases in $80 \%$ (97/121) of cases (Table 3). Malnutrition (defined broadly as a composite of Kwashiorkor/Protein Energy Malnutrition or Marasmus) was the major co-morbidity with $93 \%(57 / 61)$ of malnourished children having a comorbidity. Among non-malnourished children, comorbidity was observed in $67 \%(40 / 60)$ of cases (Table 3). Among the 111 children with lung pathology, the diagnoses given by the attending

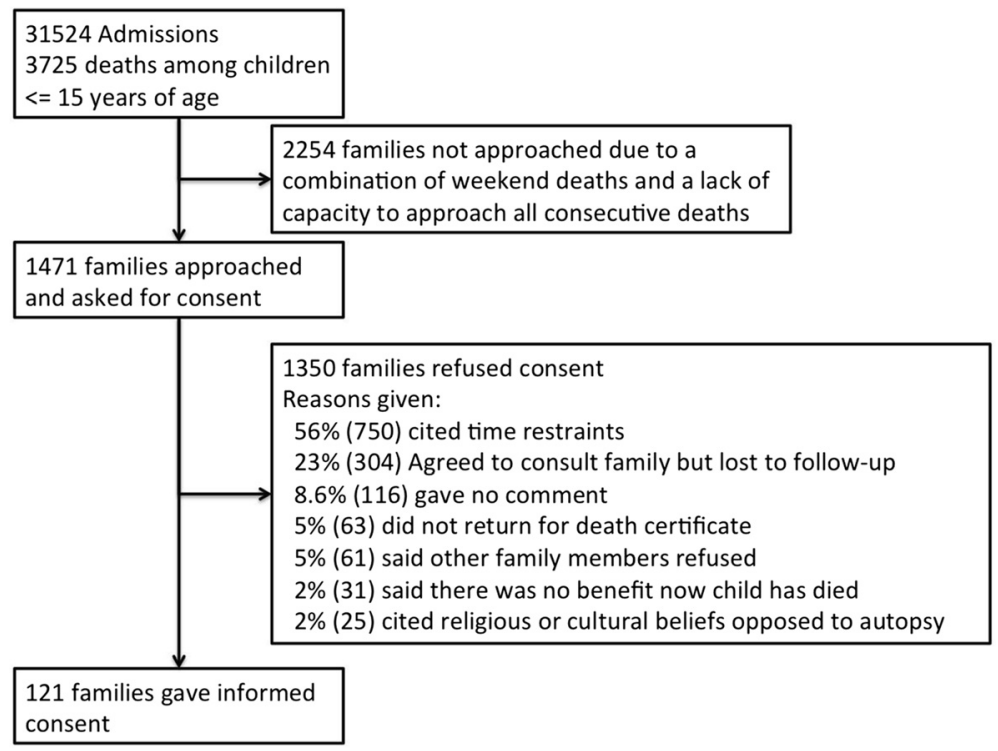

Fig. 1 Recruitment flow diagram 
Table 1 Comparison of age and sex distribution between study and population deaths

\begin{tabular}{llll}
\hline & Population $(n=3604)^{\mathrm{a}}$ & Study $(n=121)$ & $P^{\mathrm{b}}$ \\
\hline Age (months) & & $19(12-45)$ & NA \\
Median (IQR) & NA & $29 \%(35)$ & $<0.001$ \\
$<1$ years & $48.7 \%(1787)$ & $48 \%(58)$ & \\
1-4 years & $36.7 \%(1321)$ & $23 \%(28)$ & \\
4-15 years & $13.8 \%(496)$ & $64 \%(77)$ & 0.005 \\
Male sex & $50.2 \%(1810)$ & $34 \%(33 / 97)^{\mathrm{d}}$ & 0.368 \\
HIV infected & $39.4 \%(85 / 216)^{c}$ & &
\end{tabular}

${ }^{a}$ All inpatient deaths that did not take part in the study

${ }^{\mathrm{b}} \mathrm{X}^{2}$ test

'HIV status of population estimated based on previous study [16]

${ }^{\mathrm{d}}$ HIV status unavailable for 24 cases

physician indicated a range of possible comorbid conditions, with both communicable and non-communicable diseases (Table 3). Malnutrition was the predominant comorbidity, present in $50 \%(56 / 111)$ of cases with lung pathology, and was the predominant comorbidity for the five most prevalent lung pathologies: bronchopneumonia, interstitial pneumonitis, TB, CMV pneumonia and PCP (Table 3). Lung pathology was observed in $100 \%$ (15/15) of children diagnosed with other non-communicable diseases including cancer, heart disease and developmental disorders (Table 3).

Among 59 children diagnosed with histopathologically confirmed pneumonia, only $31 \%$ (18/59) were diagnosed as having pneumonia ante mortem. Other common ante mortem diagnoses among histopathologically confirmed pneumonia cases included sepsis $(22 \%, 13 / 59)$ and acute diarrhoea and dehydration (27 \%, 16/59; Table 3). Interstitial pneumonitis presented with a range of comorbidities, including acute diarrhoea and dehydration $(35 \%, 7 / 20)$, pneumonia, sepsis, meningitis and malaria (each $15 \%, 3 /$ 20). Of 10 cases of histopathologically confirmed TB infection, just $40 \%(4 / 10)$ were diagnosed ante mortem (Table 3), with only one case having initiated anti-TB therapy before they died (Table 4). The other comorbid diagnoses with confirmed TB were pneumonia $(40 \%, 4 / 10)$, sepsis $(20 \%, 2 / 10)$ and meningitis $(30 \%, 3 / 10)$ (Table 3$)$. CMV pneumonia was diagnosed in cases with gastrointestinal symptoms, and PCP was diagnosed in cases with both gastrointestinal or central nervous system symptoms, in addition to respiratory symptoms (Table 3). Of four children on anti-TB therapy when they died, none had TB pathology detected at post mortem.

\section{Molecular analysis of lung tissue}

The Xpert MTB/RIF assay detected rifampicin-sensitive $\mathrm{TB}$ in $30 \%(3 / 10)$ of lung tissue specimens in which there was histopathological evidence of pulmonary $\mathrm{TB}$ infection (Table 4). In addition, the Xpert MTB/RIF assay was positive in $30 \%(33 / 111)$ of cases in which there was no histopathological evidence of TB infection, including three cases of bronchopneumonia in which

Table 2 Lung pathology findings

\begin{tabular}{|c|c|c|c|c|c|}
\hline & \multicolumn{4}{|c|}{ Non-weighted } & \multirow{3}{*}{$\begin{array}{l}\text { Weighted for age and sex } \\
\text { Overall } \\
(n=121)\end{array}$} \\
\hline & Overall & HIV uninfected & HIV Infected & HIV status unknown & \\
\hline & $(n=121)$ & $(n=62)$ & $(n=34)$ & $(n=25)$ & \\
\hline & Count (\%) & Count (\%) & Count (\%) & Count (\%) & Count $(\%, S E)$ \\
\hline Lung pathology & $111(92 \%)$ & $53(86 \%)$ & $34(100 \%)$ & $24(96 \%)$ & $112(93 \%, 2.4)$ \\
\hline Bronchopneumonia & $60(50 \%)$ & $28(45 \%)$ & $16(47 \%)$ & $16(64 \%)$ & $52(43 \%, 4.5)$ \\
\hline Interstitial pneumonitis & $20(17 \%)$ & $9(15 \%)$ & $7(21 \%)$ & $4(16 \%)$ & $21(17 \%, 3.4)$ \\
\hline Tuberculosis (All forms) (PTB and/or EPTB) & $10(8 \%)$ & $4(6 \%)$ & $5(15 \%)$ & $1(4 \%)$ & $11(9 \%, 2.6)$ \\
\hline EPTB & $1(1 \%)$ & $0(0 \%)$ & $1(3 \%)$ & $0(0 \%)$ & $1(1 \%, 0.8)$ \\
\hline PTB & $9(7 \%)$ & $4(6 \%)$ & $4(12 \%)$ & $0(0 \%)$ & $10(8 \%, 2.5)$ \\
\hline Cytomegalovirus pneumonia & $8(7 \%)$ & $4(6 \%)$ & $3(9 \%)$ & $1(4 \%)$ & $10(9 \%, 2.5)$ \\
\hline Pneumocystis Jirovecii Pneumonia & $6(5 \%)$ & $2(3 \%)$ & $3(9 \%)$ & $1(4 \%)$ & $13(11 \%, 2.9)$ \\
\hline Pulmonary oedema & $6(5 \%)$ & $5(8 \%)$ & $0(0 \%)$ & $1(4 \%)$ & $4(4 \% .1 .7)$ \\
\hline Candidiasis & $32 \%)$ & $3(5 \%)$ & $0(0 \%)$ & $0(0 \%)$ & $1(1 \%, 0.9)$ \\
\hline Pleuritis & $2(2 \%)$ & $1(2 \%)$ & $0(0 \%)$ & $1(4 \%)$ & $1(1 \%, 0.8)$ \\
\hline Lymphoid interstitial pneumonitis & $2(2 \%)$ & $0(0 \%)$ & $1(3 \%)$ & $1(4 \%)$ & $1(1 \%, 0.7)$ \\
\hline Lobar pneumonia & $1(1 \%)$ & $0(0 \%)$ & $1(3 \%)$ & $0(0 \%)$ & $1(1 \%, 0.8)$ \\
\hline Acute respiratory distress & $1(1 \%)$ & $1(2 \%)$ & $0(0 \%)$ & $0(0 \%)$ & $3(3 \%, 1.5)$ \\
\hline Pulmonary haemorrhage & $1(1 \%)$ & $1(2 \%)$ & $0(0 \%)$ & $0(0 \%)$ & $1(1 \%, 0.7)$ \\
\hline Normal lungs & $10(8 \%)$ & $9(15 \%)$ & $0(0 \%)$ & $1(4 \%)$ & $9(8 \%, 2.4)$ \\
\hline
\end{tabular}


Table 3 Comparison between lung pathology and diagnosis given by the attending physician

\begin{tabular}{|c|c|c|c|c|c|c|c|}
\hline \multirow{3}{*}{ Attending physician diagnosis } & \multirow{3}{*}{$\begin{array}{l}\text { No lung } \\
\text { pathology } \\
(n=10)\end{array}$} & \multicolumn{6}{|c|}{ Lung pathology from post mortem } \\
\hline & & \multirow{2}{*}{$\begin{array}{l}\text { Any lung } \\
\text { pathology } \\
(n=111)\end{array}$} & \multirow{2}{*}{$\begin{array}{l}\text { Bronchopneumonia } \\
(n=59)\end{array}$} & \multirow{2}{*}{$\begin{array}{l}\text { Interstitial } \\
\text { pneumonitis } \\
(n=20)\end{array}$} & \multirow{2}{*}{$\begin{array}{l}\text { Tuberculosis } \\
(n=10)\end{array}$} & \multirow{2}{*}{$\begin{array}{l}\text { CMV } \\
\text { pneumonia } \\
(n=8)\end{array}$} & \multirow{2}{*}{$\begin{array}{l}\text { PCP } \\
(n=6)\end{array}$} \\
\hline & & & & & & & \\
\hline \multicolumn{8}{|l|}{ Communicable diseases $^{a}$} \\
\hline Pneumonia & $20 \%(2 / 10)$ & $30 \%(33 / 111)$ & $31 \%(18 / 59)$ & $15 \%(3 / 20)$ & $40 \%(4 / 10)$ & $50 \%(4 / 8)$ & $50 \%(3 / 6)$ \\
\hline Sepsis/septic shock & $40 \%(4 / 10)$ & $23 \%(25 / 111)$ & $22 \%(13 / 59)$ & $15 \%(3 / 20)$ & $20 \%(2 / 10)$ & $50 \%(4 / 8)$ & $17 \%(1 / 6)$ \\
\hline Acute diarrhoea and dehydration & $40 \%(4 / 10$ & $23 \%(26 / 111)$ & $27 \%(16 / 59)$ & $35 \%(7 / 20)$ & $0 \%(0 / 10)$ & $25 \%(2 / 8)$ & $0 \%(0 / 6)$ \\
\hline Meningitis & $30 \%(3 / 10)$ & $14 \%(15 / 111)$ & $8 \%(5 / 59)$ & $15 \%(3 / 20)$ & $30 \%(3 / 10)$ & $0 \%(0 / 8)$ & $17 \%(1 / 6)$ \\
\hline Tuberculosis & $0 \%(0 / 10)$ & $8 \%(9 / 111)$ & $3 \%(2 / 59)$ & $5 \%(1 / 20)$ & $40 \%(4 / 10)$ & $13 \%(1 / 8)$ & $17 \%(1 / 6)$ \\
\hline Malaria & $0 \%(0 / 10)$ & $5 \%(5 / 111)$ & $3 \%(2 / 59)$ & $15 \%(3 / 20)$ & $0 \%(0 / 10)$ & $0 \%(0 / 8)$ & $0 \%(0 / 6)$ \\
\hline Typhoid/enteric fever & $10 \%(1 / 10)$ & $3 \%(3 / 111)$ & $2 \%(1 / 59)$ & $5 \%(1 / 20)$ & $0 \%(0 / 10)$ & $0 \%(0 / 8)$ & $17 \%(1 / 6)$ \\
\hline PCP & $0 \%(0 / 10)$ & $3 \%(3 / 111)$ & $3 \%(2 / 59)$ & $0 \%(0 / 20)$ & $0 \%(0 / 10)$ & $25 \%(2 / 8)$ & $17 \%(1 / 6)$ \\
\hline Hepatitis & $0 \%(0 / 10)$ & $1 \%(1 / 111)$ & $2 \%(1 / 59)$ & $0 \%(0 / 20)$ & $0 \%(0 / 10)$ & $0 \%(0 / 8)$ & $0 \%(0 / 6)$ \\
\hline Tetanus & $0 \%(0 / 10)$ & $1 \%(1 / 111)$ & $2 \%(1 / 59)$ & $0 \%(0 / 20)$ & $0 \%(0 / 10)$ & $0 \%(0 / 8)$ & $0 \%(0 / 6)$ \\
\hline \multicolumn{8}{|l|}{ Non-communicable diseases ${ }^{b}$} \\
\hline $\begin{array}{l}\text { Kwashiorkor/PEM, Marasmus } \\
\text { or PCM }\end{array}$ & $40 \%(4 / 10)$ & $50 \%(56 / 111)$ & $53 \%(31 / 59)$ & $55 \%(11 / 20)$ & $80 \%(8 / 10)$ & $63 \%(5 / 8)$ & $33 \%(2 / 6)$ \\
\hline $\begin{array}{l}\text { WAZ score }<-2.0 \text { (children } \\
\text { aged }<10 \text { years old) }\end{array}$ & $78 \%(7 / 9)$ & $63 \%(57 / 91)$ & $62 \%(31 / 50)$ & $56 \%(9 / 16)$ & $75 \%(6 / 8)$ & $63 \%(5 / 8)$ & $75 \%(3 / 4)$ \\
\hline Non-malnutrition & $0 \%(0 / 10)$ & $14 \%(15 / 111)$ & $15 \%(9 / 59)$ & $10 \%(2 / 20)$ & $10 \%(1 / 10)$ & $0 \%(0 / 8)$ & $17 \%(1 / 6)$ \\
\hline Leukaemia & $0 \%(0 / 10)$ & $1 \%(1 / 111)$ & $2 \%(1 / 59)$ & $0 \%(0 / 20)$ & $0 \%(0 / 10)$ & $0 \%(0 / 8)$ & $0 \%(0 / 6)$ \\
\hline Kaposi's sarcoma & $0 \%(0 / 10)$ & $2 \%(2 / 111)$ & $2 \%(1 / 59)$ & $0 \%(0 / 20)$ & $10 \%(1 / 10)$ & $0 \%(0 / 8)$ & $0 \%(0 / 6)$ \\
\hline Cerebral palsy & $0 \%(0 / 10)$ & $3 \%(3 / 111)$ & $3 \%(2 / 59)$ & $5 \%(1 / 20)$ & $0 \%(0 / 10)$ & $0 \%(0 / 8)$ & $0 \%(0 / 6)$ \\
\hline Congestive cardiac failure & $0 \%(0 / 10)$ & $3 \%(3 / 111)$ & $3 \%(2 / 59)$ & $0 \%(0 / 20)$ & $0 \%(0 / 10)$ & $0 \%(0 / 8)$ & $17 \%(1 / 6)$ \\
\hline Rheumatic heart disease & $0 \%(0 / 10)$ & $2 \%(2 / 111)$ & $3 \%(2 / 59)$ & $0 \%(0 / 20)$ & $0 \%(0 / 10)$ & $0 \%(0 / 8)$ & $0 \%(0 / 6)$ \\
\hline $\begin{array}{l}\text { Sickle cell anaemia associated } \\
\text { cardiovascular accident }\end{array}$ & $0 \%(0 / 10)$ & $1 \%(1 / 111)$ & $2 \%(1 / 59)$ & $0 \%(0 / 20)$ & $0 \%(0 / 10)$ & $0 \%(0 / 8)$ & $0 \%(0 / 6)$ \\
\hline Primary immune deficiency & $0 \%(0 / 10)$ & $1 \%(1 / 111)$ & $0 \%(0 / 59)$ & $5 \%(1 / 20)$ & $0 \%(0 / 10)$ & $0 \%(0 / 8)$ & $0 \%(0 / 6)$ \\
\hline
\end{tabular}

Percentages indicate proportion of given lung pathology (columns) for which attending physician ascribed stated causes-of-death (rows)

${ }^{a}$ Other infectious causes-of-death without lung pathology: rabies $(n=1)$

${ }^{\mathrm{b}}$ Non-communicable disease causes-of-death with other lung pathologies not tabulated: Burkett's lymphoma with pulmonary haemorrhage and pleural inflammation $(n=1)$, hepatocellular carcinoma with pulmonary oedema $(n=1)$. Note: Causes-of-death and lung pathologies are not mutually exclusive

CMV cytomegalovirus, PCP pneumocystis Jirovecii pneumonia, $P C M$ protein-calorie malnutrition, PEM protein energy malnutrition

rifampicin resistance was detected (Table 5). The 'PowerChek ${ }^{\mathrm{TM}}$ MTB/NTM Real-time PCR assay' (Kogene, South Korea) detected MTB in 6/10 (60\%) and NTM in 2/10 (20\%) of histopathologically confirmed TB cases. Of the remaining two cases one was negative and the other flagged as invalid (Table 4). Among non-TB cases, the Kogene assay was positive for MTB in 6/111 (5\%) and positive for NTM in 34/95 (39\%) cases, with 15 negatives (14\%) and 47 invalids (47 \%). Running all invalid samples again resulted in just one additional NTM positive result. Comparing results of TB molecular analysis with lung pathology showed that molecular evidence of TB infection was readily detectable in a range of cases with different pulmonary pathologies (Table 5).

\section{Discussion}

Our study has four main findings, namely that (1) bronchopneumonia was the most prevalent lung pathology, (2) comorbidity between non-communicable and communicable diseases was found in $80 \%$ of children, (3) tuberculosis was detected in $8 \%$ of mortalities, with $9 /$ 10 cases being undiagnosed and untreated ante mortem, and (4) results of molecular analysis found evidence for MTB in 7/10 histopathologically confirmed TB cases.

The results should be viewed in terms of several limitations. Due to the generic social and resource limitations of conducting full autopsies in any geographical setting [11], our necropsy study had its focus on the chest cavity and was limited by the small sample size and the likelihood of the recruited children being older 
Table 4 Molecular analysis of lung tissue from 10 histopathologically confirmed TB cases using Xpert MTB/RIF and PowerChek ${ }^{\text {TM }}$ MTB/NTM Real-Time PCR assays

\begin{tabular}{|c|c|c|c|c|c|c|c|c|}
\hline ID & Age & Sex & HIV & ATT & ART & ZN & Xpert MTB/RIF Assay & $\begin{array}{l}\text { PowerChek }{ }^{\mathrm{TM}} \\
\text { MTB/NTM Assay }\end{array}$ \\
\hline $4 \mathrm{~B} 072$ & $3 \mathrm{yr}$ & Female & Positive & No & Yes & Negative & MTB (RIF sens) & MTB \\
\hline 4B083 & $3 \mathrm{yr}, 5 \mathrm{~m}$ & Male & Positive & No & Yes & Positive & MTB (RIF sens) & MTB \\
\hline 4B008 & $2 \mathrm{yr}, 7 \mathrm{~m}$ & Female & Negative & No & No & Positive & MTB (RIF sens) & Invalid \\
\hline 4B036 & $10 \mathrm{yr}$ & Male & Negative & No & No & Negative & Negative & NTM \\
\hline $4 \mathrm{~B} 120$ & $8 \mathrm{yr}$ & Female & Positive & No & Yes & Positive & Negative & NTM \\
\hline 4B055 & $1 \mathrm{yr}, 5 \mathrm{~m}$ & Male & Negative & No & No & Negative & Negative & MTB \\
\hline 4B064 & $10 \mathrm{yr}$ & Male & Positive & No & Yes & Positive & Negative & MTB \\
\hline 4B085 & $1 \mathrm{yr}, 4 \mathrm{~m}$ & Male & Positive & Yes & Yes & Negative & Negative & MTB \\
\hline $4 \mathrm{~B} 117$ & $5 \mathrm{~m}$ & Male & Negative & No & No & Negative & Negative & MTB \\
\hline 4B076 & $14 \mathrm{yr}$ & Female & Unknown & No & No & Negative & Negative & Negative \\
\hline
\end{tabular}

ATT anti-tuberculosis therapy, ART anti-retroviral therapy, MTB Mycobacterium tuberculosis, NTM non-TB mycobacteria, ZN Zeihl-Neelsen staining

and male. These biases are difficult to avoid on a consenting autopsy study within a community that is broadly culturally opposed to mutilation of the deceased [10]. In addition to slightly lower reservations among families over consenting for autopsy on males and older children, the recruiting clinical officer (CC) felt that families of lower socioeconomic status were more likely to consent, consistent with our recent adult autopsy study [14], but we did not collect any socioeconomic indicators such as maternal education status. Finally, the study was undertaken at a referral centre and so does not include childhood deaths within the community. It should be noted, however, that within Lusaka, referral systems are well established and most childhood deaths occur at
UTH. The findings of this study should be interpreted in light of these limitations.

The high prevalence of bacterial lung infections is alarming, as these are supposedly treatable with the range of antibiotics available at UTH, and more broadly within Zambia and regionally. In addition, two thirds of pneumonia cases were not diagnosed ante mortem. These deaths could have been influenced by increasing levels of antibiotic resistance in common community acquired pneumonia pathogens such as Haemophilius influenzae and Streptococcus pneumoniae [18]. Whilst susceptibility of these two community acquired pneumonia pathogens to front line antibiotics, such as Ampicillin and Amoxicillin, remains quite high in Africa (70-90\%) [18], a mortality

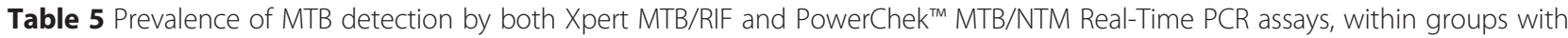
specific lung pathologies

\begin{tabular}{|c|c|c|c|}
\hline & Xpert MTB/RIF Assay & PowerChek $^{\text {TM }}$ MTB/NTM Assay ${ }^{\text {a }}$ & \\
\hline & MTB detected & MTB detected & NTM detected \\
\hline Overall & $30 \%(36 / 121)$ & $16 \%(12 / 73)$ & $62 \%(45 / 73)$ \\
\hline \multicolumn{4}{|l|}{ Lung pathology } \\
\hline Bronchopneumonia & $30 \%\left(18^{b} / 60\right)$ & $9 \%(3 / 35)$ & $63 \%(22 / 35)$ \\
\hline Interstitial pneumonitis & $60 \%(8 / 20)$ & $17 \%(2 / 12)$ & $67 \%(8 / 12)$ \\
\hline Tuberculosis (All forms) (PTB and/or EPTB) & $30 \%(3 / 10)$ & $67 \%(6 / 9)$ & $22 \%(2 / 9)$ \\
\hline EPTB & $100 \%(1 / 1)$ & $100 \%(1 / 1)$ & $0 \%(0 / 1)$ \\
\hline PTB & $22 \%(2 / 9)$ & $63 \%(5 / 8)$ & $20 \%(2 / 8)$ \\
\hline Cytomegalovirus pneumonia & $13 \%(1 / 8)$ & $0 \%(0 / 4)$ & $75 \%(3 / 4)$ \\
\hline Pneumocystis Jirovecii pneumonia & $17 \%(1 / 5)$ & $0 \%(0 / 3)$ & $67 \%(2 / 3)$ \\
\hline Pulmonary oedema & $33 \%(2 / 6)$ & $20 \%(1 / 5)$ & $80 \%(4 / 5)$ \\
\hline Candidiasis & $0 \%(0 / 3)$ & $0 \%(0 / 2)$ & $50 \%(1 / 2)$ \\
\hline Acute respiratory distress & $0 \%(0 / 1)$ & $0 \%(0 / 1)$ & $100 \%(1 / 1)$ \\
\hline Normal lungs & $20 \%(2 / 10)$ & $0 \%(0 / 7)$ & $72 \%(5 / 7)$ \\
\hline
\end{tabular}

${ }^{\mathrm{a}}$ The PowerChek ${ }^{\mathrm{TM}}$ MTB/NTM Assay gave an 'invalid' result in 48 lung tissue specimens, even after repeat analysis ${ }^{b}$ Including three rifampicin-resistant cases

EPTB extrapulmonary tuberculosis, MTB Mycobacterium tuberculosis, NTM non-TB mycobacteria, PTB pulmonary tuberculosis 
study naturally selects for severe infections that are more likely to be drug resistant, present late or be complicated by comorbidities. In the absence of full post mortem we could not determine the relative contribution of lung pathology with histopathological findings from other tissues, but comparison of lung pathology findings with clinical data identified possible comorbidity in up to $80 \%$ of cases. For a minority of cases with severe central nervous system infections or congenital heart disease, the observed lung pathology may have been secondary, but for the overwhelming number of cases, including malnourished children, the study pathologists (AS and VM) considered the lung pathology observed to be the likely primary cause of death. The observed high levels of comorbidity, in particular with malnutrition, are consistent with the high levels of malnutrition in Zambia [19]. Severely malnourished children are at increased risk of respiratory infections and associated mortality [20].

Interstitial pneumonitis is defined as a thickening of the interstitium, which damages alveoli architecture and function [21]. It can be caused by bacterial, viral or fungal lung infections, and also has a range of noninfectious aetiologies such as air pollutants. In poor communities in urban Zambia, most cooking is done on charcoal [22]. As the second most prevalent cause of fatal lung pathology, observed in $17 \%$ (20/121) of cases, the aetiology of interstitial pneumonitis in African children requires further definition, possibly through immunocytochemistry or next generation sequencing of tissue specimens. It is challenging to establish a definitive diagnosis ante mortem, with chest $\mathrm{x}$-ray manifestations having considerable overlap with other lung diseases such as TB [7].

Histopathologically confirmed TB (observation of granulomas, caseous necrosis and Langhans giant cells) was detected in $8 \%(10 / 121)$ of cases. Molecular analysis confirmed the presence of M.tb DNA in 7/10 cases, and evidenced possible NTM infection in two cases. A recent national study determined the prevalence of symptomatic NTM infection in Zambian adults to be three-fold higher than the national TB prevalence [23], which suggests NTM infections could also be a significant cause of disease in children as reviewed [24]. M.tb and NTM specific DNA was also commonly detected in the absence of histopathological evidence of TB infection, possibly indicative of latent infections, including three cases with rifampicin resistance or comorbidity where less severe TB/NTM infection was secondary to bronchopneumonia or other causes of death.

These findings seem at odds with Global Burden of Disease estimates, which do not consider TB as a notable cause of death in African children [25]. However, they are consistent with the views of other leading commentators [26-28] and our previous paediatric autopsy study (conducted between 1997-2000) which confirmed
TB as a cause of death in $20 \%(54 / 264)$ of cases, with the point prevalence being higher among HIV-uninfected children (26\%) than among HIV-infected children (18\%) [12]. Similarly in this study, we found TB in both HIVinfected and uninfected children. In Zambia, childhood TB notification rates have fallen over the last decade [29], but TB clearly remains an important cause of death. Importantly, only $10 \%(1 / 10)$ of TB cases were on TB treatment when they died, illustrating how poor TB diagnostic services are for children at UTH. Despite significant improvements in HIV prevention, diagnosis and treatment over the last decade [30], it is the slow pace of improvements in $\mathrm{TB}$ diagnostic tools and services for children [31] that has allowed TB to persist as a significant cause of death in children. A recent modelling study suggested that, for 15 high burden countries, only $35 \%$ of incident paediatric TB cases are notified globally [26].

Malnutrition was observed in $80 \%$ of histopathologically confirmed TB cases. The mortality rate on the malnutrition ward within the department of paediatrics and child health at UTH is $18 \%$, second highest only to the neonatal intensive care unit (30-50\%) [32]. More active surveillance of TB and bacterial pneumonia may be justified in malnourished paediatric admissions, and among malnourished children with TB contact, attending community clinics, at high risk of referral to UTH. There is maybe reservation to conduct invasive sampling in severely malnourished children, as it may be unpleasant for the patient. As they are on antibiotics to cover bacterial lung or gut infections and PCP, the main focus is on addressing their nutritional needs. This might mean that TB or viral respiratory infections are overlooked. The ideal specimen for TB diagnosis in young children is induced sputum [33] but spent feeding tubes could be considered as a non-additionally invasive source of gastric aspirate for TB analysis in severely ill malnourished children [16].

The point prevalence of CMV pneumonia (7\%) and PCP (5 \%) were both lower than previously reported [12], contrary to our previous study where, with a larger sample, we saw a strong association with HIV infection $(\mathrm{CMV}=22 \%, \mathrm{PCP}=29 \%)$. The previous study was undertaken prior to paediatric ART roll-out in Zambia and prior to the implementation of cotrimoxazole prophylaxis in HIV-infected children with pneumonia [12], which may have impacted on reducing CMV and PCP-associated deaths in HIV-infected children. The previous study also included only respiratory mortalities, had a lower median age, and used both immunocytochemistry as well as the observation of classic 'owls eye' inclusions to define CMV infection [12]. We have shown, in a recent population-based study [34], that early infant CMV infections are linked with impaired development of Zambian infants and, that among admitted 
infants, CMV DNAemia is associated with being underweight, meningitis, and HIV infection [35], suggesting CMV is an important determinant of health in African children. CMV pneumonia is currently treated with intravenous Ganciclovir at some centres in South Africa [36-38]. CMV was not considered ante mortem because Ganciclovir is not currently available at UTH, can cause leukopenia and neutropenia [39], and could be harmful in some HIV-infected children with a low CD4. There is a need for controlled trials for anti-CMV drugs in the African paediatric setting $[36,40]$.

\section{Conclusions}

The high level of discrepancy between clinical diagnoses and post mortem findings is alarming but is consistent with previous adult autopsy studies undertaken in Africa $[14,41-45]$, and in many cases is suggestive that patients were not receiving optimal care. Whilst some undiagnosed infections may be captured by empirical broadspectrum antibiotic therapy, important pathogens such as TB and CMV were undiagnosed and untreated in most cases. The high burden of bacterial pneumonia despite the availability of a broad panel of antibiotics raises questions over levels of drug-resistant bacterial lung infections among paediatric admissions and management of children with comorbidities. Interstitial pneumonitis is a common cause of death and its precise aetiology in African children requires further definition. TB is not considered a significant cause of death among children by the broader global health community $[1,25]$, but our demonstration of the importance of TB as a cause of death in Zambian children, first in 2002 [12] and now again over a decade later, supported by molecular analysis, suggests that more intensified TB case finding among children is needed at all levels of healthcare, with a particular focus on malnourished children. UTH and other hospitals serving high TB burden urban communities in sub-Saharan Africa might want to consider piloting intensified $\mathrm{TB}$ case finding among malnourished paediatric admissions.

\section{Acknowledgements \\ The authors would like to offer their sincerest thanks to the families of the deceased children who underwent autopsy on this study, and to state that we are actively engaged in using the data obtained from this study to design interventions that we hope will improve patient services and reduce mortalities among children at UTH. The authors also thank Kogene Biotech Company Ltd (Seoul, South Korea) for the donation of the PowerChek ${ }^{T M}$ MTB/NTM Assay and extraction kits.}

\section{Funding}

UBS Optimus Foundation (Geneva, Switzerland), the European and Developing Countries Clinical Trials Partnership (EDCTP), EuropeAID \& 'Kids Here \& There' (Columbus, Ohio, United States).

\section{Availability of data and materials}

The data presented in this paper are available from the corresponding author on request.

\section{Authors' contributions}

AZ obtained funding for the study and designed and initiated the study with $M B, A S$ and VM. MB coordinated the study as part of the TB, HIV, and respiratory portfolio of the University of Zambia and University College London Medical School Research and Training Programme (www.unza-uclms.org). AS and VM were study pathologists who did the autopsies and histopathology. CC, JT, MK and MC were involved in counselling, recruitment, molecular analysis and day-to-day management. SS, MH, MM, NK and PM were part of the advisory and monitoring group and provided input into data analyses and interpretation. MB and AZ wrote the first and subsequent drafts of the manuscript. All authors contributed to finalization of the manuscript.

\section{Competing interests}

The authors declare that they have no competing interests.

\section{Author details}

${ }^{1}$ HerpeZ, University Teaching Hospital, Lusaka, Zambia. ${ }^{2}$ University of Zambia and University College London Medical School (UNZA-UCLMS) Research and Training Programme, University Teaching Hospital, Lusaka, Zambia. ${ }^{3}$ Department of Pathology \& Microbiology, University Teaching Hospital, Lusaka, Zambia. ${ }^{4}$ Institute for Infectious Diseases, Tongji Medical College, Huazhong University of Science and Technology, Wuhan, China. ${ }^{5}$ Division of Infectious Diseases and Tropical Medicine, Medical Centre of the University of Munich, Munich, Germany. ${ }^{6}$ Therapeutic Immunology, Department of Laboratory Medicine, Department of Microbiology, and Department of Tumour and Cell Biology, Karolinska Institute, Stockholm, Sweden. ${ }^{7}$ Department of Paediatrics \& Child Health, University Teaching Hospital, Lusaka, Zambia. ${ }^{8}$ Ministry of Health, Lusaka, Zambia. ${ }^{9}$ National Tuberculosis Control Programme, Ministry of Community Development, Maternal and Child Health, Lusaka, Zambia. ${ }^{10}$ Department of Infection, Division of Infection and Immunity, University College London, and NIHR Biomedical Research centre at UCL Hospitals, London, UK.

Received: 27 April 2016 Accepted: 14 June 2016

Published online: 01 July 2016

\section{References}

1. Liu L, Oza S, Hogan D, Perin J, Rudan I, Lawn JE, et al. Global, regional, and national causes of child mortality in 2000-13, with projections to inform post2015 priorities: an updated systematic analysis. Lancet. 2015;385(9966):430-40.

2. Seddon JA, Jenkins HE, Liu L, Cohen T, Black RE, Vos T, et al. Counting children with tuberculosis: why numbers matter. Int J Tuberc Lung Dis. 2015;19 Suppl 1:9-16.

3. Bates M, Marais BJ, Zumla A. Tuberculosis comorbidity with communicable and noncommunicable diseases. Cold Spring Harb Perspect Med. 2015; 5(11). doi:10.1101/cshperspect.a017889

4. Bates M, Mudenda V, Mwaba P, Zumla A. Deaths due to respiratory tract infections in Africa: a review of autopsy studies. Curr Opin Pulm Med. 2013; 19(3):229-37.

5. Izadnegahdar R, Cohen AL, Klugman KP, Qazi SA. Childhood pneumonia in developing countries. Lancet Resp Med. 2013;1(7):574-84.

6. Graham SM. HIV-related pulmonary disorders: practice issues. Ann Trop Paediatr. 2007;27(4):243-52.

7. Pitcher RD, Beningfield SJ, Zar HJ. The chest X-ray features of chronic respiratory disease in HIV-infected children - a review. Paediatric Resp Rev. 2015;16(4):258-66

8. Snow RW, Armstrong JR, Forster D, Winstanley MT, Marsh VM, Newton CR et al. Childhood deaths in Africa: uses and limitations of verbal autopsies. Lancet. 1992;340(8815):351-5.

9. Cox JA, Lukande RL, Lucas S, Nelson AM, Van Marck E, Colebunders R. Autopsy causes of death in HIV-positive individuals in sub-Saharan Africa and correlation with clinical diagnoses. AIDS Rev. 2010;12(4):183-94.

10. Lishimpi K, Chintu C, Lucas S, Mudenda V, Kaluwaji J, Story A, et al. Necropsies in African children: consent dilemmas for parents and guardians. Arch Dis Child. 2001;84(6):463-7.

11. Mudenda V, Lucas S, Shibemba A, O'Grady J, Bates M, Kapata N, et al. Tuberculosis and tuberculosis/HIV/AIDS-associated mortality in Africa: the urgent need to expand and invest in routine and research autopsies. J Infect Dis. 2012;205 Suppl 2:S340-346. 
12. Chintu C, Mudenda V, Lucas S, Nunn A, Lishimpi K, Maswahu D, et al. Lung diseases at necropsy in African children dying from respiratory illnesses: a descriptive necropsy study. Lancet. 2002;360(9338):985-90.

13. Chintu C, Bhat GJ, Walker AS, Mulenga V, Sinyinza F, Lishimpi K, et al. Cotrimoxazole as prophylaxis against opportunistic infections in HIV-infected Zambian children (CHAP): a double-blind randomised placebo-controlled trial. Lancet. 2004;364(9448):1865-71.

14. Bates M, Mudenda V, Shibemba A, Kaluwaji J, Tembo J, Kabwe M, et al. Burden of tuberculosis at post mortem in inpatients at a tertiary referral centre in sub-Saharan Africa: a prospective descriptive autopsy study. Lancet Infect Dis. 2015;15(5):544-51.

15. Wheater PR et al. Basic histopathology: a colour atlas and text. 2nd ed. Edinburgh, New York: Churchill Livingstone; 1991.

16. Bates M, O'Grady J, Maeurer M, Tembo J, Chilukutu L, Chabala C, et al. Assessment of the Xpert MTB/RIF assay for diagnosis of tuberculosis with gastric lavage aspirates in children in sub-Saharan Africa: a prospective descriptive study. Lancet Infect Dis. 2013;13(1):36-42.

17. O'Grady J, Bates M, Chilukutu L, Mzyece J, Cheelo B, Chilufya M, et al. Evaluation of the Xpert MTB/RIF assay at a tertiary care referral hospital in a setting where tuberculosis and HIV infection are highly endemic. Clin Infect Dis. 2012;55(9):1171-8.

18. Ginsburg AS, Tinkham L, Riley K, Kay NA, Klugman KP, Gill CJ. Antibiotic non-susceptibility among Streptococcus pneumoniae and Haemophilus influenzae isolates identified in African cohorts: a meta-analysis of three decades of published studies. Int J Antimicrob Agents. 2013;42(6):482-91.

19. Munthali T, Jacobs C, Sitali L, Dambe R, Michelo C. Mortality and morbidity patterns in under-five children with severe acute malnutrition (SAM) in Zambia: a five-year retrospective review of hospital-based records (2009-2013). Arch Public Health. 2015;73(1):23

20. Lazzerini M, Seward N, Lufesi N, Banda R, Sinyeka S, Masache G, et al. Mortality and its risk factors in Malawian children admitted to hospital with clinical pneumonia, 2001-12: a retrospective observational study. Lancet Glob Health. 2016;4(1):e57-68.

21. Clement A, Nathan N, Epaud R, Fauroux B, Corvol H. Interstitial lung diseases in children. Orphanet J Rare Dis. 2010;5:22.

22. Kutsch WL, Merbold L, Ziegler W, Mukelabai MM, Muchinda M, Kolle O, et al. The charcoal trap: Miombo forests and the energy needs of people. Carbon Balance Manag. 2011;6:5

23. Chanda-Kapata P, Kapata N, Klinkenberg E, Mulenga L, Tembo M, Katemangwe $P$, et al. Non-tuberculous mycobacteria (NTM) in Zambia: prevalence, clinical, radiological and microbiological characteristics. BMC Infect Dis. 2015:15:500.

24. Lopez-Varela E, Garcia-Basteiro AL, Santiago B, Wagner D, van Ingen J, Kampmann B. Non-tuberculous mycobacteria in children: muddying the waters of tuberculosis diagnosis. Lancet Resp Med. 2015;3(3):244-56.

25. Liu L, Johnson HL, Cousens S, Perin J, Scott S, Lawn JE, et al. Global, regional, and national causes of child mortality: an updated systematic analysis for 2010 with time trends since 2000. Lancet. 2012;379(9832):2151-61.

26. Dodd PJ, Gardiner E, Coghlan R, Seddon JA. Burden of childhood tuberculosis in 22 high-burden countries: a mathematical modelling study. Lancet Glob Health. 2014;2(8):e453-9.

27. Marais BJ, Schaaf HS. Tuberculosis in children. Cold Spring Harb Perspect Med. 2014:4(9):a017855.

28. Triasih R, Robertson CF, Duke T, Graham SM. A prospective evaluation of the symptom-based screening approach to the management of children who are contacts of tuberculosis cases. Clin Infect Dis. 2015;60(1):12-8.

29. Kapata N, Chanda-Kapata P, O'Grady J, Bates M, Mwaba P, Janssen S, et al. Trends in childhood tuberculosis in Zambia: a situation analysis. J Trop Pediatr. 2013;59(2):134-9.

30. World Health Organization. Global health sector response to HIV, 2000-2015: focus on innovations in Africa, Progress report. Geneva: WHO; 2015. p. 116.

31. Detjen AK, DiNardo AR, Leyden J, Steingart KR, Menzies D, Schiller I, et al. Xpert MTB/RIF assay for the diagnosis of pulmonary tuberculosis in children: a systematic review and meta-analysis. Lancet Resp Med. 2015;3(6):451-61.

32. Kabwe M, Tembo J, Chilukutu L, Chilufya M, Ngulube F, Lukwesa C, et al. Etiology, antibiotic resistance and risk factors for neonatal sepsis in a large referral centre in Zambia. Pediatr Infect Dis J. 2016. Epub ahead of print.

33. Zar HJ, Hanslo D, Apolles P, Swingler G, Hussey G. Induced sputum versus gastric lavage for microbiological confirmation of pulmonary tuberculosis in infants and young children: a prospective study. Lancet. 2005;365(9454):130-4.
34. Gompels UA, Larke N, Sanz-Ramos M, Bates M, Musonda K, Manno D, et al. Human cytomegalovirus infant infection adversely affects growth and development in maternally HIV-exposed and unexposed infants in Zambia. Clin Infect Dis. 2012;54(3):434-42.

35. Tembo J, Kabwe M, Chilukutu L, Chilufya M, Mwaanza N, Chabala C, et al. Prevalence and risk factors for betaherpesvirus DNAemia in children $>3$ weeks and $<2$ years of age admitted to a large referral hospital in sub-Saharan Africa. Clin Infect Dis. 2015;60(3):423-31.

36. Goussard P, Kling S, Gie RP, Nel ED, Heyns L, Rossouw GJ, et al. CMV pneumonia in HIV-infected ventilated infants. Pediatr Pulmonol. 2010;45(7):650-5.

37. Hsiao NY, Zampoli M, Morrow B, Zar HJ, Hardie D. Cytomegalovirus viraemia in HIV exposed and infected infants: prevalence and clinical utility for diagnosing CMV pneumonia. J Clin Virol. 2013;58(1):74-8.

38. Zampoli M, Morrow B, Hsiao NY, Whitelaw A, Zar HJ. Prevalence and outcome of cytomegalovirus-associated pneumonia in relation to human immunodeficiency virus infection. Pediatr Infect Dis J. 2010;30(5):413-7.

39. Kimberlin DW, Jester PM, Sanchez PJ, Ahmed A, Arav-Boger R, Michaels MG, et al. Valganciclovir for symptomatic congenital cytomegalovirus disease. N Engl J Med. 2015;372(10):933-43.

40. Bates M, Musonda K, Zumla A. Human cytomegalovirus (HCMV) infection in sub-Saharan Africa. In: Manifestations of Cytomegalovirus Infections. Price P (Ed.). IntechOpen. 2013. http://www.intechopen.com/books/manifestationsof-cytomegalovirus-infection/human-cytomegalovirus-hcmv-infection-insub-saharan-africa.

41. Ageyi A, Lartey M. Spectrum of opportunistic infections causing death in patients with AIDS in Ghana: Correlation of clinical diagnosis with autopsy results. San Francisco: XI CROI; 2009. p. 8-11.

42. Martinson NA, Karstaedt A, Venter WDF, Omar T, King P, Mbengo T, et al. Causes of death in hospitalized adults with a premortem diagnosis of tuberculosis: an autopsy study. AIDS. 2007;21(15):2043-50.

43. Murray J, Sonnenberg P, Nelson G, Bester A, Shearer S, Glynn JR. Cause of death and presence of respiratory disease at autopsy in an HIV-1 seroconversion cohort of southern African gold miners. AIDS. 2007;21 Suppl 6:S97-S104.

44. Ordi J, Ismail MR, Carrilho C, Romagosa C, Osman N, Machungo F, et al. Clinico-pathological discrepancies in the diagnosis of causes of maternal death in sub-Saharan Africa: retrospective analysis. PLoS Med. 2009;6(2): e1000036.

45. Rana FS, Hawken MP, Mwachari C, Bhatt SM, Abdullah F, Ng'ang'a LW, et al. Autopsy study of HIV-1-positive and HIV-1-negative adult medical patients in Nairobi, Kenya. J Acquir Immune Defic Syndr. 2000;24(1):23-9.

\section{Submit your next manuscript to BioMed Central and we will help you at every step:}

- We accept pre-submission inquiries

- Our selector tool helps you to find the most relevant journal

- We provide round the clock customer support

- Convenient online submission

- Thorough peer review

- Inclusion in PubMed and all major indexing services

- Maximum visibility for your research

Submit your manuscript at www.biomedcentral.com/submit
) Biomed Central 